\title{
Psychological Benefits of Ornamental Plants Used in Office Environments
}

\author{
Anca Mariana HUSTI ${ }^{1}$, Ioana CONȚIU, Mălina RADU, Ioana NEACŞU and Maria CANTOR* \\ Faculty of Horticulture, University of Agricultural Sciences and Veterinary Medicine Cluj-Napoca, 3-5 \\ Mănăștur Street, 40037 Cluj-Napoca, Romania; \\ ${ }^{*}$ Corresponding author, e-mail: marcantor@yahoo.com
}

Bulletin UASVM Horticulture 72(1) / 2015

Print ISSN 1843-5254, Electronic ISSN 1843-5394

Doi:10.15835/buasvmcn-hort:10625

\begin{abstract}
In an urbanized context, the need for a thorough understanding of the relationship between plants and human well-being becomes more and more important. It is documented that plants in the work environment bring a number of benefits, not only aesthetic but also psychological and physical benefits. The present study sought to determine if ornamental plants have positive effects on a wide range of factors such as productivity, mood states, creativity and stress on employees in an real organizational context. Questionnaire with 15 statements was used as method to examine the employees perceptions, applied before, after the installation of plants for each office and in swich phase. The study results were examined to determine if are statistically significant differences between the two groups at every stage. There were significant differences between the experimental and control group over the work environment. Research has found that for a better perceived working environment is a close link between creativity, reduced stress and job satisfaction. Results support the evidence of the psychological benefits of ornamental plants on employees and a general preference for plants. The direct impact of these benefits is on well-being and general performance of companies and the incorporation of ornamental plants in the workplace is deemed imperative for the future organizations to achieve the desired results.
\end{abstract}

Keywords: benefits, employees, indoor environments, ornamental plants, quality of life.

\section{INTRODUCTION}

Plants refresh a person's mind and introduce an element of nature, even in an office building, an environment in which each person work mechanical. Incorporating nature in interior design can play an important role in creating an environment that promotes physical and mental health of the occupants (Shibata 2001, 2004; Yannick et al., 2009).

Stress-the disease of the century with its various forms, is produced by artificial environments in which modern man lives. In fact, man is exposed to new situations by modern life, in terms of the psychological aspects of wellbeing and health. Data provided by different organizations such as WHO shows that are increasing the health problems and discomfort of those who work and spend more than $80 \%$ of the time at work and especially in modern buildings. An employee spends in average around 8 hours per day at work. Spending so much time at work, it becomes a significant space to promote employee health. This fact should emphasize indeed the importance of indoor environmental quality. This trend gets increasingly more and in most areas of the world.

Many traditional cultures with strong ties to the natural surroundings were under assault of modernization, development and environmental degradation, which are linked conclusively to an increase in feelings of isolation and depression in these communities (Mayer and Frantz, 2004; Speldewinde et al. 2009, 2011; Van Haaften and Van De Vijver, 1996). Thus, to investigate the dimension to which ornamental plants affects the wellbeing of those working in the "hermetic" spaces is very important. 
Since the early 1970s the benefits of plants on humans were recognized through a substantial scientific research. On the second half of the century research report a growing awareness that designing interior spaces with nature in mind can have broad-ranging positive impact on human quality of life (Ulrich, 1984; Kellert, 2005).

Doxey et al. (2009) asserts that passive encounters with nature can improve levels of satisfaction with job and home life and can affect mood and cognition. Other studies have shown that the presence of indoor plants may have positive effects on individuals moods, recovery from mental fatigue, stress levels, and creative task performance (Dijkstra et al., 2008).

Researches with important results based on plants at work focused on two indoor environmental factors respectively physical and psychosocial. In 2002, psychologist Gifford states that physical factors in work environment affect productivity and employee satisfaction. Research conducted on plants and their benefits are important and contribute to increased use of ornamental plants for solving environmental and health problems.

The study conducted by Roelofsen (2002) reveals that reducing complaints, absenteeism and increase employee productivity is influenced by the work environment and how it is improved. Thomsen et al. (2011), in their study regarding people-plant relationships found that plants are an integrated part of a workplace and is closely related to how the work environment is viewed by employees as well as their wellbeing.

Smith and Pitt (2009) in their research claim that offices which include a reasonable number of plants are preferred by employees as opposed to those without plants. Work environment can be considered as an intrinsic factor contributing to greater involvement from employees and resulting in increased productivity.

Man, in terms of contemporary civilization has gradually disconnected more and more of nature creating a structural imbalance with more hours spent in indoor environments, especially at work and time coercion. This urbanized lifestyle can have negative effects on personal health, for this reason the present study investigate the psychological potential of ornamental plants in indoors. The main goal was to determine if ornamental plants have positive effects on various factors.

\section{MATERIALS AND METHODS}

The experience for the present study was held at a private company in Cluj Napoca, the sample included office workers and the test comprises two offices receiving generic names OPIS 1 and OPIS 2.

As initial phase the management team of the company was contact being asked for permission through e-mail and set up a meeting in which it was described in what consists the study and its purpose. They have allowed employees to participate and to complete the questionnaire during working hours. In the second stage and the employees were informed about the study, objectives and which would be their involvement. All participants gave their consent to be part of this study. Participation was voluntary and anonymous.

The participants were 16 employees with age beetwen 25 to 48 . The design included 2 groups: group OPIS 1 with $\mathrm{n}=8$, represented the control group and group OPIS 2 with $n=8$, the experimental group. The study consisted in a pre-test, post-test and swiched test design with a Likert scale.

Ornamental plants were installed in the design of test office and that without plants was considered control office. Name OPIS 1 was assigned to the control office while for test office was given the name OPIS 2 . Offices were selected based on the fact they met certain criteria, similar characteristics such as layout, size, space shall, number of employees and their activities.

Test office was decorated with indoor plants in pots: Sansevieria trifasciata, Spathiphyllum wallissi, Dracaena deremensis, Ficus benjamina. Ornamentals were placed both on the floor and shelves, ranging in size, from $75 \mathrm{~cm}$ to $115 \mathrm{~cm}$, for example Sansevieria $80 \mathrm{~cm}$, Spathiphyllum $75 \mathrm{~cm}$, Dracaena $85 \mathrm{~cm}$ and Ficus $115 \mathrm{~cm}$. Ornamental plants were installed in OPIS 2 for a period of two months. After two months was made the switch between the test and control offices. Indoor plants were placed by the researcher and their maintenance was provided too.

As work method has been used questionnaires, completed anonymously by both offices occupants. Questionnaires included 15 statements about different aspects of the office environment and 
demographic information. Questionnaires were applied three times for each office. The first phase was before the installation of plants, the second one after the installation of plants and the last stage when the switched took place. The given statements are detailed in Tabel 1:

Participants were given two options: to respond to each item using one of the answer options available for all questions, or had the alternative of not responding. It is noted that no participant chose not to answer at all the statements referred.

Evaluation of responses was achieved through an approach of ordinal Likert scale (Likert, 1932) with five values 1 = 'strongly disagree', 2 = 'disagree', 3 = 'neutral', 4 ='agree', 5 = 'strongly agree', to measure respondents' attitudes by asking the extent to which they agree or disagree with a statement. The design of the questionnaire had the form observed in Table 2 .
Data were transferred and centralized in a Microsoft Excel file and afterwards analyzed using the SPSS platform 2001. It was used a 2 -Tailed Z-test, alpha being set at 0.05 . Data were analyzed to compare the results of employees who worked in offices with ornamental plants and employees who worked in offices without plants.

\section{RESULTS AND DISCUSSION}

Based on the literature review such as studies of Dravigne et al., (2008) who found statistically significant differences in perceptions of overall life quality and job satisfaction or Bringlismark et al. (2007) who found that the number of plants in proximity to office workers' desks had statistically reliable associations with productivity, it was assumed that the results for the office with plants would be more positive than for the one without plants. The first, second and third questionnaire was returned by all employees from both groups, according to the design chosen for this study with three different experimental stages: pretest - 3xn,

Tab. 1. Statements to which respondants answered.

\begin{tabular}{cc}
\hline Nr. crt & Items \\
\hline 1. & Office is a pleasant and comfortable place in which to work \\
\hline 2. & My workplace make me feel effective \\
\hline 3. & I feel positive and productive in my work environment \\
\hline 4. & My work makes me feel tense \\
\hline 5. & I feel enthusiastic at work \\
\hline 6. & My work environment contributes to my new, useful and original ideas \\
\hline 7. & At work I come with creative solutions \\
\hline 8. & I feel under pressure at work \\
\hline 9. & Work environment is not stressful \\
\hline 10. & My workplace include good ambient features \\
\hline 11. & My personal privacy is enough for me in my work environment \\
\hline 12. & An mork area I can have a private conversation \\
\hline 13. & My work space increase communication \\
\hline 14. & I would like to have more plants at office \\
\hline 15. &
\end{tabular}

Tab. 2. The questionnaire design with 15 statements for each a five-point Likert scale answer.

\begin{tabular}{ccccccc}
\hline \multicolumn{9}{c}{ Control Group } \\
\hline Statement & \multicolumn{3}{c}{ Scale } \\
\hline Nr.crt. & & $\begin{array}{c}\text { Strongly } \\
\text { Disagree }\end{array}$ & Disagree & Neutral & Agree & $\begin{array}{c}\text { Strongly } \\
\text { Agree }\end{array}$ \\
\hline 1. & $\begin{array}{c}\text { Office is a pleasant and comfortable } \\
\text { place in which to work }\end{array}$ & $\mathrm{O}$ & $\mathrm{O}$ & $\mathrm{O}$ & $\mathrm{O}$ & $\mathrm{O}$ \\
\hline
\end{tabular}


posttest - 3xn and swiched test - 3xn, were received in total 72 questionnaires, 24 for each stage.

Participants from OPIS 1 as was mentioned were used as controls, and the first phase of the analysis of results was to establish if there were statistically significant differences in respondents' answers to the questionnaire 1 compared with the one from the second stage. Questionnaires from pretest and post-test phase were provided by researcher to employees from OPIS 1, completed in a suitable timeframe.

In the physical environment of the control group were not made any changes being expected that the employees responses to the questionnaire during the pretesting stage to be similar to those of the questionnaire 2. Considering these foundations has been formulated the following hypothesis:

'Between the participants' responses of OPIS 1 to the questionnaire 1 and 2 will be no statistically significant difference".

Questionnaire was administered to the control group employees, and yet there are differences between participants' responses to the questionnaire 1 and 2 . It can be assumed that this is due to the fact that the participants who responded to the questionnaires were subjected to different work pressures. The test used did not provide results statistically significant for any of the variables. This demonstrates that the hypothesis: "Between the participants' responses of OPIS 1 to the questionnaire 1 and 2 will be no statistically significant difference" is supported by the data. These data also provides premise that any changes in responses from participants of OPIS 2 is due to the introduction of plants in interior design.

For the experimental group the questionnaires were distributed in phase 1 and were completed before installing the plants and the second phase completed after the plants were placed in office.

Because it was added a new physical environmental factor at work it was expected that there may be a difference in responses between the two stages. In this case, the following hypothesis was formulated:

'Between the OPIS 2 participants' responses will be significant difference between the pre-test and post-test phase".

For the formulated hypothesis data show that there were statistically differences between participants responses from pre-test and poststage test in the experimental group. It seems that in this case the presence of plants makes a difference between the factors tested. With the first item, $74 \%$ of respondants in phase 2 agreed and strongly agreed, while in phase 1, 81\% disagreed and strongly disagreed. The pattern continue also for the other statements.

Due to the fact that the plants were placed in OPIS 2 , the questionnaire was administered again and it was expected that between responses of OPIS 1 and OPIS 2 there will be differences. The following hypothesis was formulated:

'Between participants' answers from OPIS1 and OPIS 2 will be significant differences".

The first item regarding whether the work environment is pleasant and comfortable followed this model. Six participant from office $1(\mathrm{~V} 1, \mathrm{SDV}=2.6)$ disagreed that the office was comfortable. Participants in office 2(V3,STDV=1.8), 7 agreed or strongly agreed with the item, whereas in office 1 only 2 agreed. For control group 51\% represent disagreement with statement 1 , while $46 \%$ from experimental group agreed with the first item. Results from OPIS 2 demosntrate the positive influence of plants on different variables such as comfort and pleasentness. The results can be seen also in Figure 1. The two samples are significantly different.

The results for the statement 3 „I feel positive and productive in my work environment" $12 \%$ of occupants disagreed in OPIS 1 , and in OPIS $2,16 \%$ agreed, as is show in Figure 2. The two samples are significantly different. Results suggest that ornamental plants plays an important role in the productivity of participants.

Results from z-test demosntrates that statement „I feel under pressure at work” are significant, more participants, 7 agreeing or strongly agreeing in OPIS 1 the control group than on OPIS 2 , just 1 . In OPIS $1,31 \%$ disagreed or strongly agreed with the statement and $37 \%$ from OPIS 2 agreed or strongly agreed (Fig. 3a). The results show that the presence of plants affected this item, suggesting that participants in office with plants appreciate less that their work environment contribute to feelings of pressure. Result is in agreement with the research results made by Lohr et al. (1996) and Dijkstra et al. (2008), who assert that environments where plants are present stress is reduced. This pattern 


\section{Office is a pleasant and comfortable place in which to work}

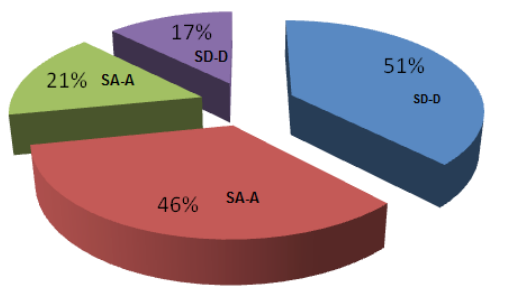

V1, V3 - stage 2

V2, V4 - stage 3

Fig. 1. Participants answers to first statement from the 2 and 3 stage of the applied questionnaire. Note: V1 represent control group without plants, $\mathrm{V} 2=$ swiched group with plants, $\mathrm{V} 3=$ experimental group with plants, V4 = swiched group without plants, SD-D = strongly disagree- disagree, $\mathrm{SA}-\mathrm{A}=$ strongly agree-agree .

was followed also about the other statements, the results show that employees in the OPIS 2 feel more effective, positive, comfortable and creative than those in the control office. Likewise, those from OPIS 2, 17\% agreed or strongly agreed and have found that the environment was more aesthetically pleasing than those in office without plants who $21 \%$ disagreed and strongly disagreed with the statement.

Regarding the increase of privacy by plants, the results have not demonstrated to be true this statement in the phase of swiched offices, when the plants from experimental group were included in control office (Fig. 3b). These results may be because the varieties of plants used were small and medium.

To item „I would like to have more plants to the office" (Fig. 3b) answers for: strongly agree and agree from 8 persons were higher in the control group than in the experimental group where 5 participants responded strongly agree and agree. This is probably because the plants introduced into the experimental group was close to optimal and participants in the control group, saw the plants in the OPIS 2 , considering that the plants would be a plus also for their office. The data demonstrate that there is a general preference for working environments with plants (Smith and Pitt, 2009).

\section{CONCLUSIONS}

Due to the fact that this study was conducted in a real context of work, it can be said that offer

\section{I feel positive and productive in my work environment}
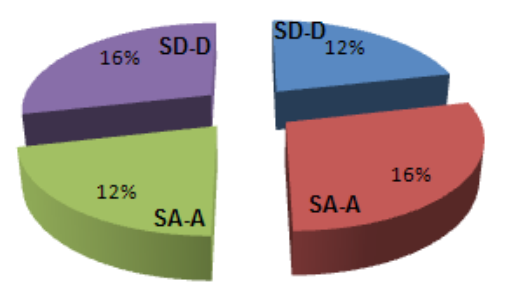

V1, V3 - stage 2

$\mathrm{V} 2, \mathrm{~V} 4$ - stage 3

Fig. 2. Participants answers to third statement from the 2 and 3 stage of the applied questionnaire. Note: V1 represent control group without plants, V2 = swiched group with plants, V3 = experimental group with plants, V4 = swiched group without plants, SD-D= strongly disagree- disagree, $\mathrm{SA}-\mathrm{A}=$ strongly agree-agree.

additional practical perspectives of benefits of indoor plants. This data supports the evidence of the psychological benefits of ornamental plants on humans and a general preference for plants identified previously by different research.

Participants in this study perceived that the office in which plants were included, aesthetic quality is higher $17 \%$ strongly agreed and agreed, indicating that plants could be regarded as a measure to improve the environment in which they operate.

This research shows that the office with plants can have a positive effect on employees, regarding comfort, mood states, creativity, productivity and reduced levels of stress. From the results of the study various conclusions can be drawn, and that one where ornamental plants are used indoors could be a cost effective way and without too much added cost to improve employees well-being and productivity in general, is very important for organizations.

Human-plants relationship is a major concern of the contemporary world, as confirmed by this study. Plants as an integrated environment are healthy and essential to the prosperity and quality of life.

The findings help to identify and arrange those gaps in the area of interest. These results provide and obtain new and in depth knowledge about human-plant relationship, facilitate decision making, support interdisciplinary and give an 


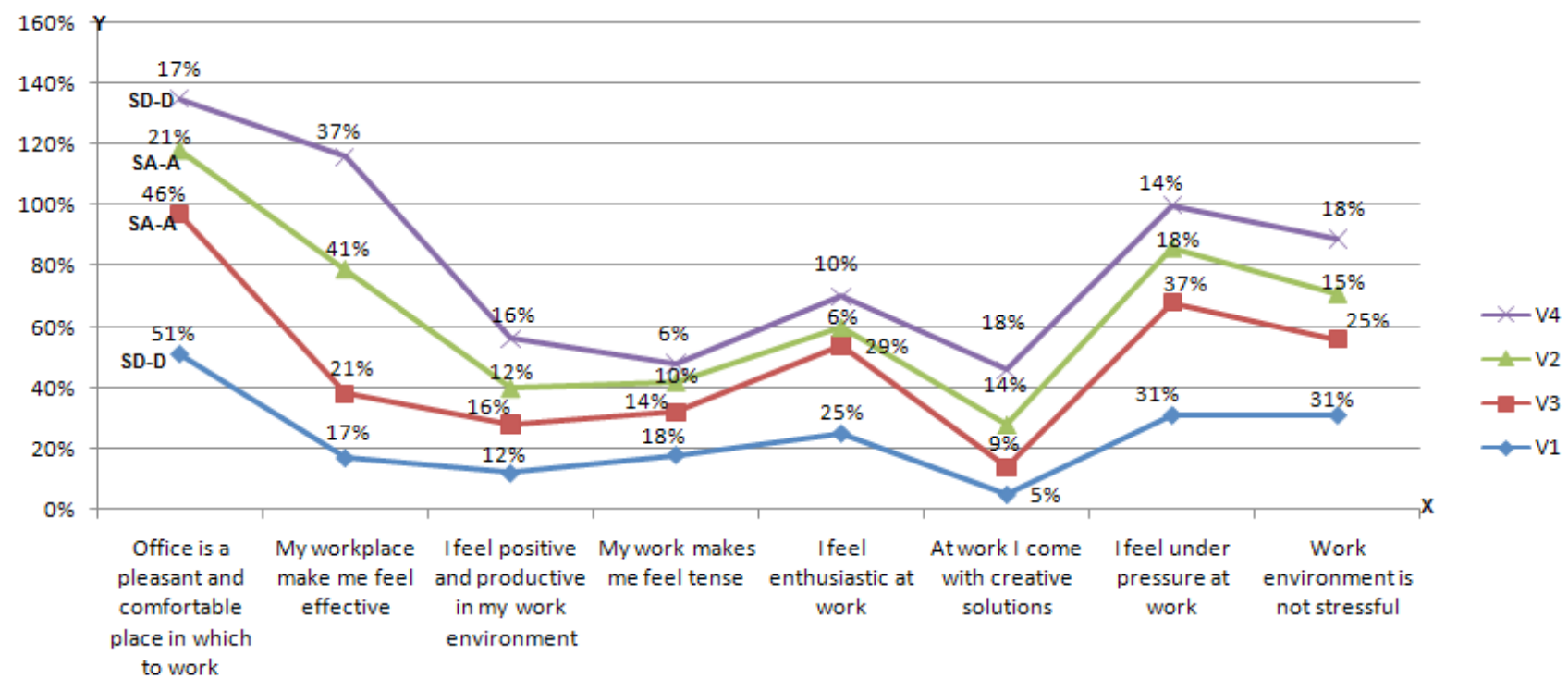

Fig. 3a. Questionnaires results for control and experimental group phase with and without plants and swiched stage.

Note: According to the chart the X-axis constitute the questionnaire statements, where $\mathrm{Y}$ - show percentage of the participants answers at items, V1 = control group without plants, V2 = swiched group with plants, V3 = experimental group with plants, V4 = swiched group without plants, SD-D = strongly disagree-disagree, $\mathrm{SA}-\mathrm{A}=$ strongly agree-agree.

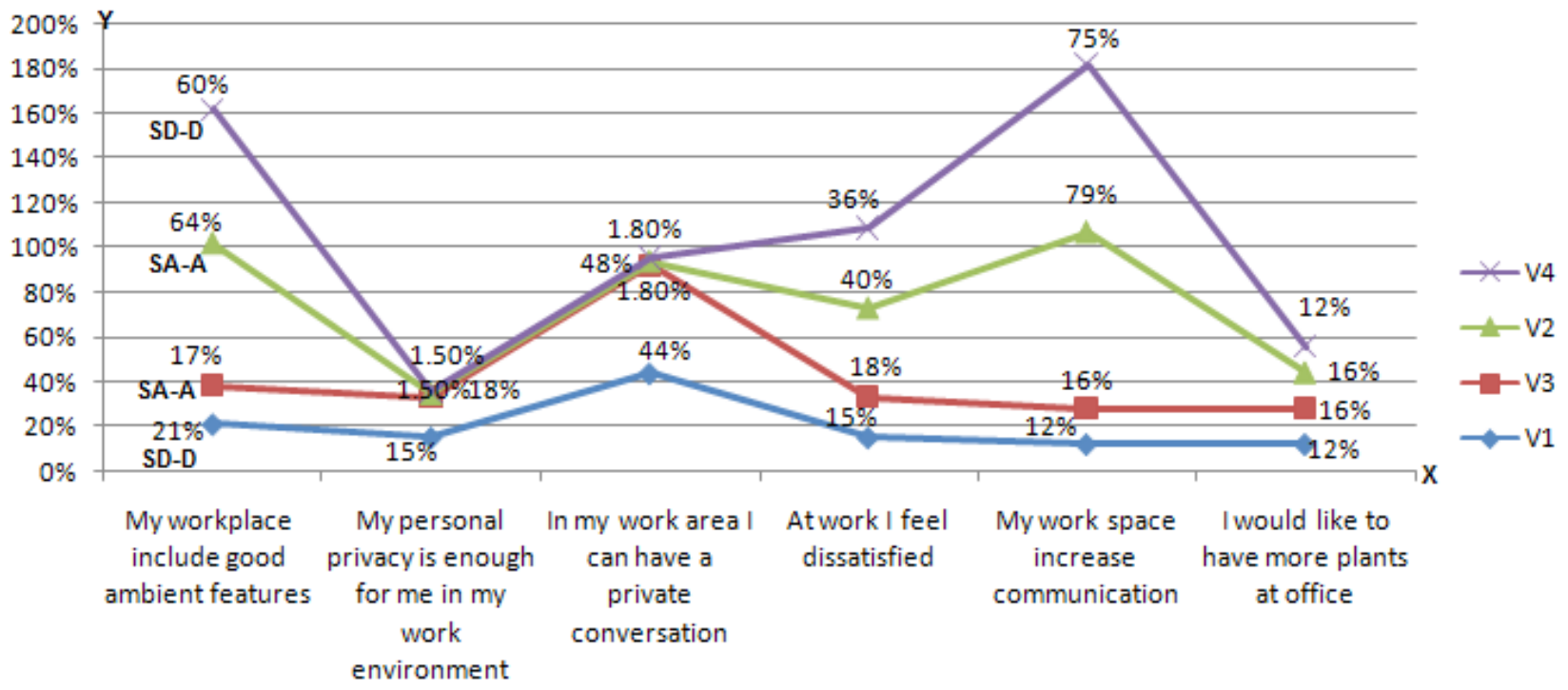

Fig. 3b. Questionnaires results for control and experimental group, phase with and without plants and swiched stage.

Note: According to the chart the X-axis constitute the questionnaire statements, where $\mathrm{Y}$ - show percentage of the participants answers at items, V1 = control group without plants, $\mathrm{V} 2=$ swiched group with plants, $\mathrm{V} 3=$ experimental group with plants, V4 = swiched group without plants, $\mathrm{SD}-\mathrm{D}=$ strongly disagree-disagree, $\mathrm{SA}-\mathrm{A}=$ strongly agree-agree. 
important basis for initiation of theoretical and empirical work.

The necessity of this research is to be extended. This can be achieved by applying the study to a larger number of respondents and thus to a higher number of work environments. Also other research is needed to validate and extend these findings further.

Acknoledgements. This paper was published under the frame of European Social Fund, Human Resources Development Operational Programme 2007-2013, Project no. POSDRU/159/1.5/ S/132765.

\section{REFERENCES}

1. Dijkstra K, Pieterse ME, Pruyn A (2008). Stressreducing effects of indoor plants in the Built healthcare environment. Preventive Medicine 47: 279-283.

2. Doxey JS, Waliczek TM, Zajicek JM (2009). The Impact of Interior Plants in University Classrooms on Student Course Performance and on Student Perceptions. HortScience 44(2): 384-391.

3. Gifford R (2002). Environmental psychology: Principles and practice. 3rd ed. Optimal Books, Colville, Washington.

4. Kellert S (2005). Designing and understanding the human-nature connection.Washington Island.

5. Likert R (1932). A Technique for the Measurement of Attitudes, Archives of Psychology, 140.

6. Mayer FS, Frantz CMP (2004). The connectedness to nature scale: ameasure ofindividuals'feelingin community with nature. J. Environ. Psychol. 24: 503-515.
7. Roelofsen P (2002). The impact of office environments on employee performance: the design of the workplace as a strategy for productivity enhancement. Journal of Facilities Management, Vol. 1:247-264.

8. Shibata S, Suzuki N (2001). Effects of indoor foliage plants on subjects' recovery from mental fatigue. North American Jr. of Psychology 3(2):385-396.

9. Shibata S, Suzuki N (2004). Effects of an indoor plant on creative task performance and mood. Scandinavian Journal of Psychology 45:373-381.

10. Smith A, Pitt M (2009). Sustainable workplaces: Improving staff health and wellbeing using plants. Journal of Corporate Real Estate, Vol. 11, No. 1.

11. Speldewinde PC, Cook A, Davies P, Weinstein P (2009). A relationship between environmental degradation and mental health in rural Western Australia. Health Place 15: 865-872.

12. Speldewinde PC, Cook A, Davies P, Weinstein P (2011). The hidden health burden of environmental degradation: disease comorbidities and dryland salinity. EcoHealth 8: 82-92.

13. Thomsen JD, Sonderstrup-Andersen HHK, Muller R (2011). People-plant relationships in an office workplace: perceived benefits for the workplaces and employees. HortScience 46 (5): 744-752.

14. Ulrich RS (1984). View through a window may influence recovery from surgery. Science 224:420-421.

15. Van Haaften EH, Van De Vijver FJR (1996). Psychological consequences of environmental degradation. J. Health Psychol. 1: 411-429.

16. Yannick J, Brengman M, Willems K, Kathleen W (2009). The effects of urban retail greenery on consumer experience: Reviewing the evidence from a restorative perspective. Urban Forestry and Urban Greening 9:57-64. 